\title{
Acute laryngeal obstruction in rheumatoid arthritis
}

\section{H Bossingham, F G Simpson}

\begin{tabular}{|l|}
\hline In patients with \\
rheumatoid arthritis \\
who are dyspnoeic or \\
wheezy cricoarytenoid \\
joint disease must be \\
excluded by \\
laryngoscopy
\end{tabular}

130 Abbott Street, Cairns, Queensland 4870, Australia D H Bossingham,

rheumatologist

Cairns Base Hospital, Esplanade, Cairns, Queensland 4870, Australia

F G Simpson, director of

thoracic medicine

Correspondence to:

Dr Bossingham.

BMf 1996;312:295-6
Disease of the cricoarytenoid joints in rheumatoid arthritis has been recognised for many years ${ }^{1}$ and may present with hoarseness, pain in the larynx, or the sensation of a foreign body in the throat. The prevalence of involvement has been assessed at between $26 \%$ and $69 \%$ in relatively small groups of patients. ${ }^{23}$ No relation with age, disease duration, or disease severity has been shown. Cricoarytenoid joint involvement is best assessed by appropriate questioning and direct or indirect laryngoscopy. ${ }^{3}$ Loss of movement may then be apparent, as may local swelling or erythema.

Cricoarytenoid disease may present acutely or intermittently, presenting difficulties in diagnosis and treatment. ${ }^{46}$ We report a case where abnormal respiratory function tests suggested an alternative diagnosis and led to an acute presentation and near fatal outcome.

\section{Case report}

This $\mathbf{5 5}$ year old woman had developed seropositive, erosive rheumatoid arthritis in 1966 at the age of 26 .
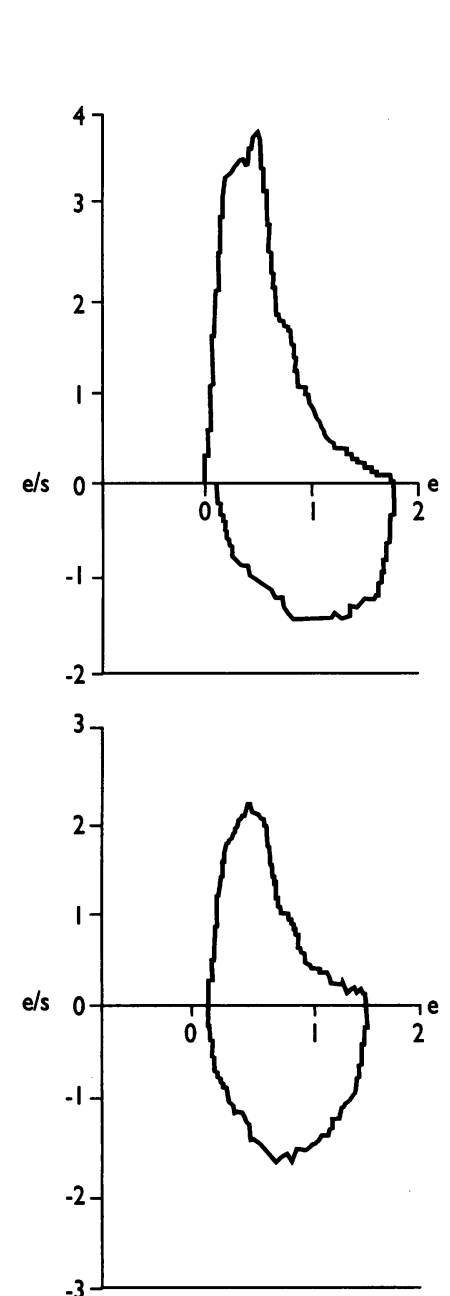

\begin{tabular}{|c|c|c|}
\hline & Value & $\begin{array}{l}\% \\
\text { Predicted }\end{array}$ \\
\hline Forced expiratory volume in I $s(1)$ & 1.32 & 60 \\
\hline Forced vital capacity (I) & 1.79 & 68 \\
\hline $\begin{array}{l}\text { Forced expiratory flow at } 50 \% \text { of } \\
\text { lung volume (1/s) }\end{array}$ & 1.34 & 43 \\
\hline Peak expiratory flow rate $(1 / s)$ & 3.95 & 74 \\
\hline Peak inspiratory flow rate $(1 / s)$ & 1.62 & \\
\hline $\begin{array}{l}\text { Forced inspiratory flow at } 50 \% \text { of } \\
\text { lung volume }(1 / \mathrm{s})\end{array}$ & 1.09 & \\
\hline Total lung capacity (I) & 3.77 & 86 \\
\hline Residual volume (I) & 1.98 & 122 \\
\hline $\mathrm{Va} / \mathrm{TLC}$ & 0.53 & \\
\hline DLCO & 12.18 & 52 \\
\hline KCO & 5.22 & 96 \\
\hline $\begin{array}{l}\text { Forced expiratory flow at } 50 \% \text { of } \\
\text { lung volume/Forced inspiratory flow } \\
\text { at } 50 \% \text { of lung volume }\end{array}$ & 1.23 & \\
\hline $\begin{array}{l}\text { Forced expiratory volume in I s/peak } \\
\text { expiratory flow rate }\end{array}$ & 5.7 & \\
\hline
\end{tabular}

$\begin{array}{lll} & \text { Value } & \% \\ \text { Forced expiratory volume in I s (I) } & 1.05 & 47 \\ \text { Forced vital capacity (I) } & 1.49 & 56 \\ \text { Forced expiratory flow at } 50 \% \text { of } & & \\ \quad \text { lung volume (I/s) } & 1.09 & 35 \\ \text { Peak expiratory flow rate (I/s) } & 2.23 & 41 \\ \text { Peak inspiratory flow rate (I/s) } & 1.62 & \\ \text { Forced inspiratory flow at 50\% of } & & \\ \quad \text { lung volume (I/s) } & 1.36\end{array}$

Fig 1-Results of full pulmonary function tests performed in February 1994 at the time of intermittent wheeze (top) and results of spirometry performed through tracheostomy (bottom). $V_{a}=$ accessible alveolar volume; TLC=total lung capacity; $D L C O=$ diffusion capacity of lung for carbon monoxide, or TLCO (carbon monoxide transfer factor); $K C O=$ transfer coefficient
Her disease deteriorated and required treatment with non-steroidal anti-inflammatory drugs and then, by 1980 , with prednisolone. Methotrexate was started in 1990 and discontinued in 1992. She had undergone splenectomy in 1968, presumably for Felty's syndrome, and bilateral pantalar fusions in 1990 for severe hindfoot symptoms.

She was first seen by DHB in 1993 for assessment of deteriorating joint symptoms. Rheumatoid nodules, bilateral parotid swellings, and scleromalacia were noted, together with a destructive deforming arthritis particularly affecting the hands, feet, and shoulders. Investigation showed haemoglobin $118 \mathrm{~g} / \mathrm{l}$, leucocytes $14 \cdot 4 \times 10^{9} / 1$, platelets $689 \times 10^{12} / 1$, erythrocyte sedimentation rate $84 \mathrm{~mm}$ in the first hour, $C$ reactive protein $49 \mathrm{mg} / \mathrm{l}$, antinuclear antibody titre 640 (homogenous/ speckled pattern), rheumatoid factor positive. Treatment with azathioprine and prednisone was started.

The history of chest disease began at age 49 . There were no childhood problems, no family history of chest disease, and no industrial or animal exposure. She complained of chronic dyspnoea with acute exacerbations precipitated by coughing or the sensation of aspirating saliva. There were no nocturnal symptoms but she had smoked over 40 cigarettes daily between the ages of 20 and 35. Examination showed generalised late inspiratory crackles throughout both lung fields. There was no clubbing or wheeze. Respiratory function testing (fig 1) showed a mixed obstructive and restrictive picture with raised residual volume but not total lung capacity. There was poor gas mixing with a low alveolar ventilation/total lung capacity ratio, but gas transfer was normal. Taken with the clinical findings these results were thought to be consistent with a diagnosis of bronchiolitis obliterans.

In March 1994 she was admitted with acute stridor and was grossly cyanosed. Emergency bronchoscopy showed fixed adduction of the vocal cords, which were parted with the bronchoscope, giving immediate relief of symptoms. She was started on $40 \mathrm{mg}$ prednisone daily, but four days later her stridor recurred, tracheostomy was performed, and she has chosen to maintain this ever since. Subsequent pulmonary function tests, performed through the tracheostomy, showed persistence of the previous abnormalities. In particular, the flow volume loop was very similar to that in the original test (fig 1). Laryngoscopy performed later showed persistent adduction of the vocal cords, with limited movement.

\section{Discussion}

Dyspnoea in a patient with rheumatoid arthritis may have many causes related to the disease, its complications, or its treatment or may be entirely incidental. In this patient investigation suggested one cause, bronchiolitis obliterans, but this did not explain her acute dyspnoeic episodes, which had been ascribed to "asthma" and had been treated as such.

Arthritis of the cricoarytenoid joint is a rare cause of dyspnoea; involvement in rheumatoid arthritis is probably frequently overlooked if the published figures for incidence are true. ${ }^{23}$

Bilateral paralysis of the vocal cords produces characteristic changes in the flow volume loop. ${ }^{7}$ Upper 


\begin{tabular}{|l|}
\hline Causes of dyspnoea in rheumatoid \\
arthritis \\
Incidental causes \\
Complicating rheumatoid arthritis: \\
Cardiac: \\
Pericardial effusion \\
Aortic, mitral valve disease \\
Medication: \\
Methotrexate fibrosis \\
Gold fibrosis \\
Asthma induced by non-steroidal \\
anti-inflammatory drugs \\
Pneumonitis induced by non-steroidal \\
anti-inflammatory drugs \\
Penicillamine bronchiolitis \\
Pulmonary: \\
Pleural effusion or thickening \\
Pulmonary hypertension \\
Pulmonary nodules \\
Upper lobe fibrosis \\
Bronchiectasis/chronic suppuration \\
Fibrosing alveolitis/lymphocytic interstitial \\
pneumonia \\
Bronchiolitis obliterans \\
Cricoarytenoid arthritis \\
\hline
\end{tabular}

airway obstruction is suggested by a forced expiratory flow at $50 \%$ lung volume/forced inspiratory flow at $50 \%$ lung volume greater than $\mathbf{4}$ or forced expiratory volume in 1 second/peak expiratory flow rate greater than $10 \mathrm{ml} / \mathrm{min}$. Both these were normal on the original tests. Peak inspiratory flow was low but there is no established normal range and the value was not sig- nificantly better when measured through the tracheostomy. Intermittent laryngeal obstruction caused by cricoarytenoid arthritis is not emphasised in standard texts and will not be detected by respiratory function tests.

Cricoarytenoid arthritis may be chronic and present for many years without becoming apparent. Its presentation may be acute, and, if not recognised and treated, fatal. Common symptoms such as hoarseness may be absent and simple tests for laryngeal obstruction can give normal results. In rheumatoid arthritis parenchymal lung disease may coexist with cricoarytenoid arthritis. We suggest that the investigation of dyspnoea, even when intermittent, in a patient with rheumatoid arthritis should routinely include laryngoscopy.

We thank Dr D Laing for his help in the management of this case.

Funding: None.

Conflict of interest: None.

1 Darke CS, Wolman L, Young A. Laryngeal stridor in rheumatoid arthritis. $B M F 1958$;ii:1279-84.

2 Lofgren RH, Montgomery WW. Incidence of laryngeal involvement in rheumatoid arthritis. N Engl I Med 1962;267:193-5.

3 Geterud A. Rheumatoid arthritis in the larynx (MD thesis). University of Goteborg, 1991.

4 Tenholter JBM, vanBuchen FL, vanBeusekom HJ. Crico-arytenoid arthritis may be a case of emergency. Clin Rheumatol 1988;7:288-90.

5 Pinals RS. Rheumatoid arthritis presenting with laryngeal obstruction. $B M F$ 1966;i:842.

6 Geterud A, Ejell H, Mansson I, Sondburg N, Bake B, Bjelle A. Severe airway obstruction caused by laryngeal rheumatoid arthritis. $\mathcal{F}$ Rheumatol 1986;13: 948-51.

7 Bolliger CT, Sopko J, Maurer P, Soler M, Perruchoud A. The flow-volume loop in bilateral vocal cord paralysis. Chest 1993;104:1302-4.

(Accepted 3 August 1995)

\section{Controversies in Management}

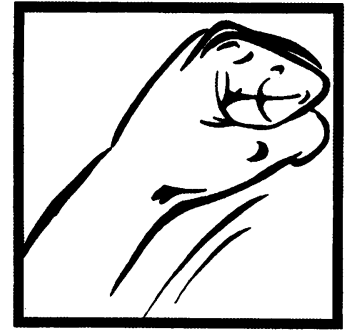

This is one in an occasional series of articles examining some of the difficult decisions that arise in medicine

NHS Centre for Reviews and Dissemination, University of York, York YO1 5DD

Trevor A Sheldon, professor and director

Avon Health, Bristol BS2 8EE

Angela Raffle, consultant in public health medicine

Directorate of Clinical Radiology, Bristol Royal Infirmary, Bristol BS2 8HW Iain Watt, consultant clinical radiologist

Correspondence to:

Professor Sheldon.

$B M \Im$ 1996;312:296-8

\section{Department of Health shoots itself in the hip}

\section{Why the report of the Advisory Group on Osteoporosis undermines evidence based purchasing}

\section{Trevor A Sheldon, Angela Raffle, Iain Watt}

The report of the Advisory Group on Osteoporosis represents a step back in the way the Department of Health develops policy on health technologies. ${ }^{1}$ It ignores the mechanisms which have been established to provide research input into decision making, ${ }^{2}$ it fails to review the evidence in a systematic way, ${ }^{3}$ and it recommends clinical policies which are not justified by the available evidence. We can see why the current arrangements within the Department of Health for considering issues related to screening have been described as "wasteful and confusing; they blur responsibility and invite conflict."

\section{Ploy to avoid considering costs and benefits}

The advisory group was asked to "establish what information about osteoporosis is available, what research is being conducted and what further work needs to be done, and to report to ministers." In making recommendations about the use of bone densitometry and about the number of machines the report goes well beyond this brief.

What is wrong with the advisory group's recommendations? Few would disagree that the $50 \%$ or so of hip fractures in older women associated with low bone density are a major cause of suffering and a cost to the NHS. Nor would many disagree that bone density measurement is a valuable diagnostic tool for clinicians treating patients with bone disease or that it is important for research. However, the value of bone density measurement to identify patients who could be encouraged to take preventive action (exercise, dietary change, and drug treatments such as hormone replacement therapy) against a fracture which they may or may not suffer more than 20 years in the future is highly uncertain.

The advisory group asserts that "population screening" for osteoporosis is not worth while but that bone densitometry should be used for testing patients likely to have low bone mass. They include in this group women at the time of the menopause in order to aid clinical decision making, and they say that $45 \%$ of women have "strong risk factors." Yet if certain groups are known to have low bone density what is to be gained by testing them? If it is not known, then how are the benefits of testing this group any more certain than for the general population? The semantic sidestep whereby widespread testing of healthy people is 